\title{
Does Family with Children Need Information about Infectious Disease?
}

\author{
Michiko Nohora1, Junko Kurita², Tamie Sugawara ${ }^{3 *}$, Yasushi Ohkusa ${ }^{3}$ \\ ${ }^{1}$ Tokyo Kasei University, Tokyo, Japan \\ ${ }^{2}$ The Graduate School of Health Sciences, Ibaraki Prefectural University of Health Sciences, Ibaraki, Japan \\ ${ }^{3}$ National Institute of Infectious Diseases, Tokyo, Japan \\ Email: ^tammy@nih.go.jp
}

How to cite this paper: Nohora, M., Kurita, J., Sugawara, T. and Ohkusa, Y. (2018) Does Family with Children Need Information about Infectious Disease? Journal of Biosciences and Medicines, 6, 53-63. https://doi.org/10.4236/jbm.2018.612005

Received: November 2, 2018

Accepted: December 4, 2018

Published: December 7, 2018

Copyright (c) 2018 by authors and Scientific Research Publishing Inc. This work is licensed under the Creative Commons Attribution International License (CC BY 4.0).

http://creativecommons.org/licenses/by/4.0/ (c) (i) Open Access

\begin{abstract}
This paper reports a study of the necessity of providing information that is of the most concern of caregivers: health management, responses to sudden onset, and outbreaks of infectious diseases. We asked users and providers of Child Care Support Service in ward A of Tokyo, as respondents, whether they would like to receive information related to infectious diseases. Of questionnaires sent by mail to 383 providers and 3101 users, we received 18 responses from providers and 88 responses from users. All providers and users were required to provide information related to infectious diseases. The most often reported responses were "straight-out hand washing, mask wearing, gargling, and disinfection", followed by "voluntary restraint of outside activities", and "measures for illnesses of the family or children." Results show that caregivers would like to receive information about infectious diseases because they have many health management concerns about their children.
\end{abstract}

\section{Keywords}

Caregivers, Child Care Support, Infectious Diseases, Outbreak Situation, Prevention

\section{Introduction}

In a society with a declining birthrate, providing safety and security to children is an important social demand and aspect of child care support. In Japan, the share of mothers who continued working after their first childbirth was only $29.7 \%$ in 1992 . This figure rose dramatically to $53.1 \%$ in 2015 [1]. Governments have been multiplying and expanding nursery schools to accommodate the rapidly raise number of working mothers. In addition, improving nursery school 
quality is necessary.

Infants are physically and immunologically vulnerable, and are therefore easily infected. They are frequently infected when living in groups, as they do at nursery schools, but are also infected in family situations. Moreover, they sometimes have infection-associated complications. Caregivers should arrange their working schedules and family nursing when children show illness if caregivers have job. However, the most frequent trouble in child care cited by caregivers is the response to sudden onset of infectious diseases in children [2].

Caregivers can take nursing leave up to five days per year in Japan, during which time caregivers of preschool children can care and nurse illnesses or injured children. The Declining Birthrate White Paper in 2017 in Japan reported that the rates of caregivers taking such leave were $5.2 \%$ for male caregivers and 25.3\% for female caregivers in 2014 [3]. Therefore, it is expected to be difficult to rearrange working schedules even if family nursing leave is guaranteed by law. A child care support policy intended to alleviate some anxiety of caregivers might not be promoted or realized.

Moreover, children in nursery schools or schools are easily infected because of their group life situation. Outbreaks of infectious diseases might widen at those facilities [4]. They have therefore adopted some measures for infectious diseases and use the Nursery School Absenteeism Surveillance System (NSASSy) to support the detection of outbreak situations in the community [5]-[10].

Many studies conducted worldwide have specifically examined school absenteeism [11]-[16], but NSASSy uses aspects of Japan's own unique nursery school culture. Caregivers of children who are absent from nursery school usually report their symptoms and diseases if they were diagnosed by a doctor to their nursery school. Therefore, we can conduct surveillance by symptom as well as diagnosed disease using information from caregivers. School surveillance in other parts of the world [11]-[16] cannot achieve similar coordination because they have no culture of notification from caregivers about the reason for absence.

Therefore, at best, such school surveillance counts reflect the total number of absences irrespective of the reason, or absences caused by illness or influenza-like-illness only. Moreover, those studies specifically examine schools, not nursery schools. In this sense also, NSASSy is unique.

Through NSASSy, nursery schools and schools are made aware of the situation in the surrounding community and are informed as staff and as caregivers. Particularly, because caregivers come to nursery schools twice a day to leave their children and to take charge of them, nursery schools can provide some information about infectious diseases to caregivers every day. Moreover, public health centers monitor the circumstances at each facility and give timely advice to them [17].

However, for security reasons, caregivers cannot access NSASSy directly. Moreover, caregivers of children who belong to no nursery school are unable to receive such information from NSASSy. 
This paper reports a study assessing the necessity of information that is of the most concern of caregivers: health management, responses to sudden onset, and outbreaks of infectious diseases, under corporation with the Child Care Support Service.

The Child Care Support Service was established in 1994 by Ministry of Labour (at that time) in Japan to combine working and child care or nursing care in women. Since 2015, it was one of the Community Child Rearing Support project available to all caregivers with children irrespective of their working status. Half of them are provided by local governments. The other half are operated by commissioned contractors from local governments including non-profit organizations. The organization matches users who require child care support and providers who can support child care. The Child Care Support Service takes care of children before opening and after closing of nursery schools, leaving children off and taking charge of them at a nursery school, and taking care of children when nursery schools are closed or when caregivers need a break from their responsibilities. The service established in 833 municipalities throughout Japan as of the end of 2017; those account for about $45 \%$ of all municipalities in Japan [18]. As of March 2016, there were 0.6 million users and providers in Child Care Support Service nationwide. The share was about $12 \%$ assuming each users has one preschool child.

To date, child care support has specifically addressed persons requiring medical support or disabled people [19] [20]; rarely have studies specifically examined caregivers who have received some services. No report of the relevant literature describes a study of child care support for children in general.

\section{Methods}

Subjects of this survey of the necessity for information of infectious diseases were participants of Child Care Support Service in ward A in Tokyo, Japan. We asked users and providers of the Child Care Support Service, as respondents, whether they would like to receive information related to infectious diseases. The questionnaire, administered anonymously, included questions related to age, gender, frequency of Child Care Support utilization, type of (nursery) school that the child attends, utilization of services for sick children, whether the (nursery) school that the child attends provides information related to infectious diseases, information about the child health condition when Child Care Support Services are used, records of child vaccination, child vaccination for influenza, and internet utilization through smart phones. Regarding infectious diseases, we asked them about the necessity of information related to infectious diseases, concern about outbreak situations in the (nursery) school that children attend, and whether it is possible to arrange a schedule when a child has high fever. Additionally, we asked for their responses while providing information in a free format.

The requesting document was sent to users and providers form the Child Care 
Support Services in December 2017. It asked them to reply the questionnaire anonymously on the internet.

\section{Ethics}

This study was approved by the Ethical Committee of Tokyo Women's Medical School on 24 November, 2017 with approval number 4561.

\section{Results}

Of questionnaires sent by mail to 383 providers and 3101 users from Child Care Support Service in ward A of Tokyo. We received 18 (6.0\%) responses from providers and $88(2.8 \%)$ responses from users.

Table 1 presents the results. All providers were women. Most providers were in their 50s (44.4\%), followed by those in their 40s (27.8\%). In addition, 82 users were women. Users in their 30 s accounted for $48.3 \%$ of all users followed by those in their 40s. Regarding the frequency of service provision, more than four times each month was the highest $(77.8 \%)$. However, regarding frequency of usage, none was the highest (30.3\%), followed by utilization in the past $(21.3 \%)$, and more than four times $(20.2 \%)$. Users who responded that they had never used the service included many users who had joined the service recently, but who had not used it.

Table 1. Questionnaire responses from providers $(n=18)$ and users $(n=88)$.

\begin{tabular}{|c|c|c|c|c|c|}
\hline & & Providers & $\%$ & Users & $\%$ \\
\hline Basic characteristic & & 18 & & 88 & \\
\hline \multirow[t]{2}{*}{ Gender } & Male & 0 & 0.0 & 6 & 6.7 \\
\hline & Female & 18 & 100.0 & 82 & 93.3 \\
\hline \multirow[t]{5}{*}{ Age class } & $20 \mathrm{~s}$ & 0 & 0.0 & 2 & 2.2 \\
\hline & $30 \mathrm{~s}$ & 2 & 11.1 & 42 & 48.3 \\
\hline & $40 \mathrm{~s}$ & 5 & 27.8 & 40 & 44.9 \\
\hline & $50 s$ & 8 & 44.4 & 3 & 3.4 \\
\hline & $60 \mathrm{~s}$ & 3 & 16.7 & 1 & 1.1 \\
\hline \multirow[t]{5}{*}{ Frequency of service } & $\begin{array}{l}\text { More than four } \\
\text { times a month }\end{array}$ & 14 & 77.8 & 18 & 20.2 \\
\hline & Sometimes & 3 & 16.7 & 15 & 16.9 \\
\hline & None & 1 & 5.6 & 26 & 30.3 \\
\hline & Used it in the past & 0 & 0.0 & 19 & 21.3 \\
\hline & Unanswered & 0 & 0.0 & 10 & 11.2 \\
\hline \multirow[t]{4}{*}{$\begin{array}{c}\text { Type of school } \\
\text { (multiple responses) }\end{array}$} & Nursery schools & 16 & 88.9 & 47 & 52.8 \\
\hline & Kodomoen & 10 & 55.6 & 14 & 15.7 \\
\hline & Kindergarten & 6 & 33.3 & 10 & 12.4 \\
\hline & Elementary schools & 5 & 27.8 & 18 & 20.2 \\
\hline
\end{tabular}




\section{Continued}

\begin{tabular}{|c|c|c|c|c|c|}
\hline & $\begin{array}{c}\text { Special supporting } \\
\text { schools }\end{array}$ & 0 & 0.0 & 0 & 0.0 \\
\hline & Others & 1 & 5.6 & 4 & 4.5 \\
\hline \multirow{3}{*}{ (nursery) school place } & None & 6 & 33.3 & 10 & 11.2 \\
\hline & In A ward & 17 & 94.4 & 75 & 85.4 \\
\hline & Outside A ward & 1 & 5.6 & 6 & 6.7 \\
\hline \multirow{3}{*}{$\begin{array}{l}\text { Utilization of services } \\
\text { for sick children }\end{array}$} & Not got to & 0 & 0.0 & 7 & 7.9 \\
\hline & Yes & 13 & 72.2 & 48 & 53.9 \\
\hline & No & 5 & 27.8 & 40 & 46.1 \\
\hline $\begin{array}{l}\text { Information provision } \\
\text { about children's health } \\
\text { condition When Child Care } \\
\text { Support services used }\end{array}$ & Yes & 18 & 100.0 & 39 & 43.8 \\
\hline \multirow{3}{*}{$\begin{array}{l}\text { Record of children's } \\
\text { vaccination }\end{array}$} & No & 0 & 0.0 & 49 & 56.2 \\
\hline & Yes & & & 88 & 100.0 \\
\hline & No & & & 0 & 0.0 \\
\hline \multirow{3}{*}{$\begin{array}{l}\text { Vaccination for } \\
\text { influenza in children }\end{array}$} & Every year & 4 & 22.2 & 62 & 69.7 \\
\hline & None & 14 & 77.8 & 15 & 18.0 \\
\hline & Sometimes & 0 & 0.0 & 11 & 12.4 \\
\hline Internet use & Yes & 14 & 77.8 & 86 & 97.8 \\
\hline through smart phone & No & 4 & 22.2 & 2 & 2.2 \\
\hline \multirow{4}{*}{$\begin{array}{l}\text { Request information } \\
\text { of infectious diseases }\end{array}$} & & & & & \\
\hline & Yes & 18 & 100.0 & 88 & 100.0 \\
\hline & No & 0 & 0.0 & 0 & 0.0 \\
\hline & Yes & 8 & 44.4 & 73 & 83.1 \\
\hline \multirow{2}{*}{$\begin{array}{l}\text { Are you concerned about } \\
\text { outbreaks in the (nursery) } \\
\text { school that children attend? }\end{array}$} & None & 10 & 55.6 & 8 & 9.0 \\
\hline & $\begin{array}{l}\text { Child does not attend } \\
\text { (nursery) school }\end{array}$ & 0 & 0.0 & 7 & 7.9 \\
\hline \multirow{3}{*}{$\begin{array}{c}\text { Does the (nursery) school } \\
\text { that children attend provide } \\
\text { information about infectious } \\
\text { diseases? }\end{array}$} & Yes & 6 & 33.3 & 66 & 74.2 \\
\hline & No & 12 & 66.7 & 15 & 18.0 \\
\hline & $\begin{array}{l}\text { Child does not attend } \\
\text { (nursery) school }\end{array}$ & 0 & 0.0 & 7 & 7.9 \\
\hline $\begin{array}{l}\text { Are you concerned about } \\
\text { outbreak in the (nursery) }\end{array}$ & Yes & & & 87 & 98.9 \\
\hline school that children attend? & No & & & 1 & 1.1 \\
\hline \multirow{3}{*}{$\begin{array}{l}\text { Can you arrange your } \\
\text { schedule when your child } \\
\text { has a high fever? }\end{array}$} & Yes & & & 52 & 59.6 \\
\hline & No & & & 15 & 16.9 \\
\hline & Neither & & & 21 & 23.6 \\
\hline
\end{tabular}


Related to the type of (nursery) school children attended, preschool facilities such as nursery schools, kindergarten or kodomoen (a nursery schools and kindergarten hybrid) were the highest for both providers and users. However, there were cases many elementary school and even preschool children for whom no facilities were available to attend.

Almost all (nursery) schools the children attended were located in ward A. In addition, $72.2 \%$ of providers and $53.9 \%$ of users registered sick child care. The reason of $46.1 \%$ of users did not register sick child care might be the simultaneous registration of usual care and sick child care, which had been abandoned recently.

All providers report the children's health condition when Child Care Support Services are used. However, about half of users (56.2\%) only report a child's condition to the provider. That result might reflect the fact that many users have never used the service. All users managed the child vaccination history. Results show that $77.8 \%$ of providers did not take influenza vaccinations every year. However, $69.7 \%$ of users received them every year. Many providers and users used the internet through smart phones for information such as weather forecasts.

All providers and users required to receive information related to infectious diseases. Although $55.6 \%$ of providers were unconcerned about outbreaks at the (nursery) school that children attended, $83.1 \%$ of users were concerned. In addition, $66.7 \%$ of providers did not know the situation of infectious diseases at the (nursery) school that the child attended from the (nursery) school, but $74.2 \%$ of users reported that they were notified. Particularly, almost all users were concerned about clusters of illness at the (nursery) school that the child attended. Actually, 59.6\% of users reported being able to arrange their schedule to care for a child with a high fever. However, $16.9 \%$ of users reported being unable to do so.

Figure 1 presents the number of categorized caregivers' responses about receiving information about infectious diseases as "precaution", "countermeasure", "children", and "family" when using a free response format. "Children" was the highest, but "precaution" followed. More detailed classifications are shown in Figure 2. There were 12 classifications: straight-out hand washing, mask wearing, gargling, and disinfection; voluntary restraint of outside activities; measures for illnesses of the family or children; measures in the caregivers' workplace; reminders and information provided about their environment; situational awareness of outbreaks; checks and responses for children's onset; referral to a doctor; mental attitude; decisions about whether a child goes to a nursery school or being absent from it, or going back earlier; timely treatment of vomiting; and decisions related to vaccination.

The most often reported classification was "straight-out hand washing, mask wearing, gargling, and disinfection", followed by "voluntary restraint of outside activities", and "measures for illnesses of the family or children." 


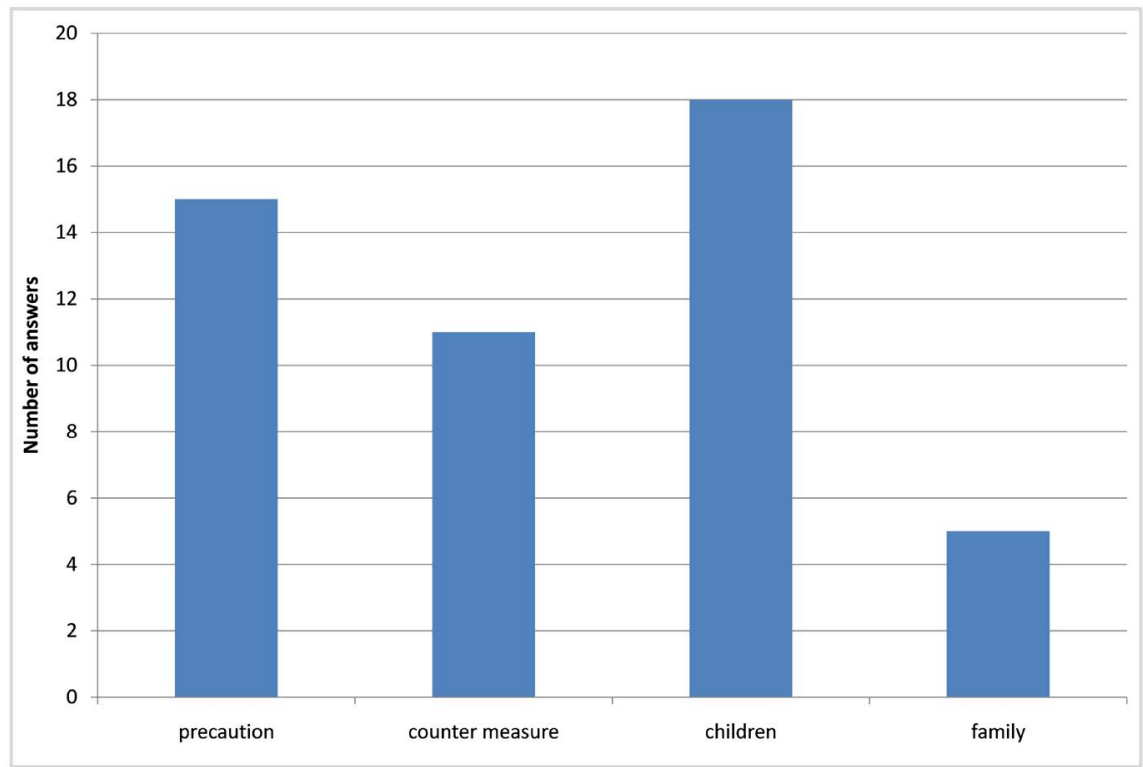

Figure 1. Categorized caregivers' responses about receiving information about infectious diseases in free format, (Number of responses). Note: horizontal axis labels denote "precautions", "countermeasures", "children", and "family".

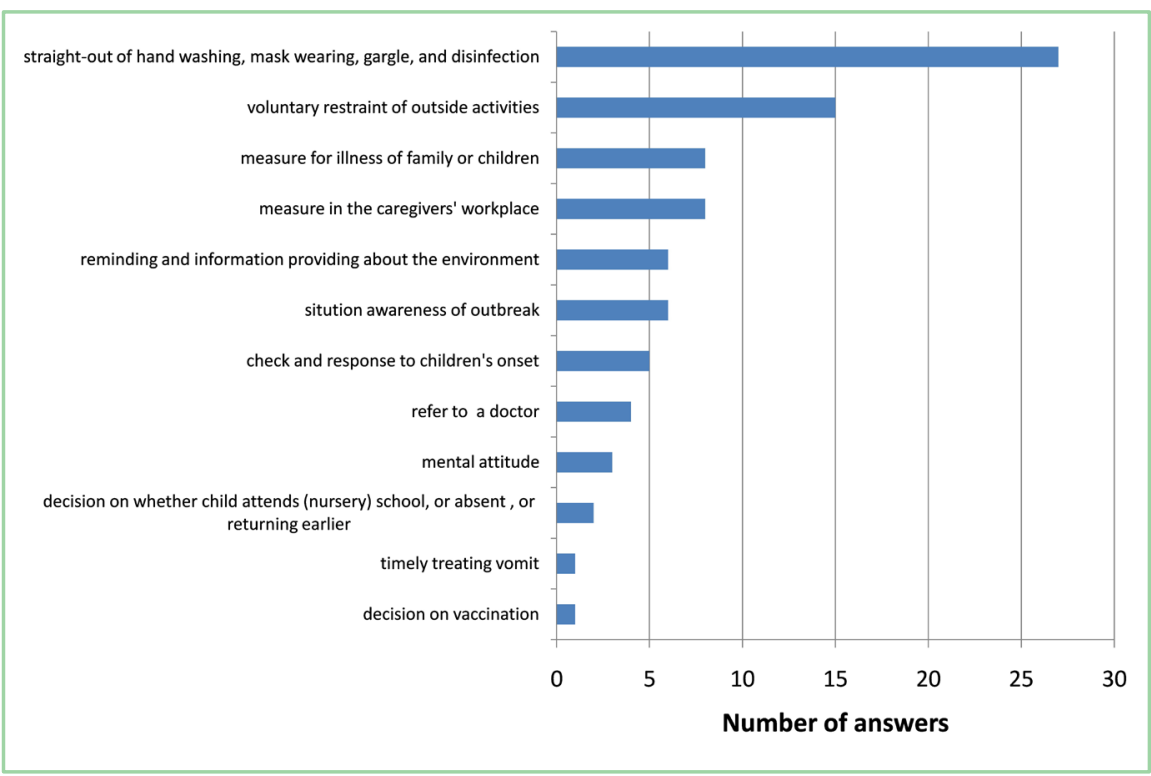

Figure 2. Number of detailed categorized caregivers' responses about whether they receive information related to infectious diseases in free format.

\section{Discussion}

Child Care Support Service includes many users whose preschool children go to nursery school, kindergarten or do not attend either one. In other words, it includes not only working caregivers but also non-working caregivers. One might access caregivers of preschool children who attend nursery school or kindergarten, but access to caregiver of preschool children who do not attend either is apparently very difficult. Collaboration with the Child Care Support Service 
enables us to access caregivers of preschool children irrespective of where the preschool children attend or not. Therefore, we can evaluate our project while minimizing bias from sampling by collaboration. It covered about $24 \%$ of preschool children residing in ward A if we assume all users have one preschool child. It is perhaps the largest database of preschool children other than that of the local government of ward A.

Because Figure 2 depicts the top three responses were "straight-out hand washing, mask wearing, gargling, and disinfection", "voluntary restraint of outside activities", and "measures for illnesses of the family or children," it might indicate that behavioral change for measurement in families. It might reflect measurement for infectious disease at (nursery) schools. However, "measures in the caregivers' workplace", which was the fourth most frequent response, is interesting. Onset in children usually occurs suddenly. It is very difficult for caregivers to rearrange a working schedule if a child shows sudden onset. For that reason, they sometimes cannot be absent from work. In such cases, those ill children can also not be absent from nursery schools and visit a doctor.

If caregivers know the community situation related to infectious diseases before sudden onset in children, then caregivers can inform their workplace before onset about possibility of absence to care for a child. The workplace might rearrange their working schedule or take family nursing leave into consideration if so. Finally, when often absent from their workplace, children can be absent from nursery school and can then visit a doctor. Therefore, timely information related to common infectious diseases in infants in a community situation can ease the disruption caused by the work absence of caregivers. Caregivers can also take family nursing leave more readily.

Moreover, such information might contribute to avoidance of outbreak in (nursery) schools and therefore in communities by the absence of ill children, and increased quality of life of ill children themselves by earlier consultation with a doctor.

Results of this study demonstrate that both providers and users of the Child Care Support Services would like to receive timely information about infectious diseases. Such information is expected to improve many aspects of health management for children. Caregivers also expect it to be useful.

In the near future in Japan, declining quality of nursery schools might occur because of the expanded quantity of nursery schools. To allay such concerns, information related to infectious diseases can provide support to caregivers. Moreover, we demonstrated that providers looking after children use such information to protect themselves. Particularly, providers who look after several children might be able to diffuse outbreaks among classes or (nursery) schools. Both results can reduce outbreaks occurring in the wider community.

Because this study was performed in a small community, a ward, we cannot generalize the results nationwide. We presume that the necessity of caregivers was affected by employment, family composition, going to a (nursery) school 
outside their school zone, and the participation rate of preschool children in nursery school or kindergarten. We must conduct similar studies throughout Japan, to evaluate these results. However, because the Child Care Support Services were established per municipality as described previously, it is apparently difficult to collaborate with the Child Care Support Services beyond the municipality. That is expected to be our next research challenge.

Moreover, we must consider the possibility of similar system other than that in Japan. We presume some necessity for information of infectious diseases even in other countries. However, it needs real-time surveillance system like $(\mathrm{N})$ SASSy. Construction of real-time surveillance system might be first step for the similar system in other countries.

\section{Conclusion}

Providing safety and security to children is a challenge for all society. Results show that caregivers would like to receive information about infectious diseases because they have many health management concerns about their children. Hereinafter, based on the observed necessity, we expect to provide information related to infectious diseases and then evaluate its usefulness. Finally we attempt to expand such services year-round and throughout Japan to realize a society in which all children can grow healthily.

\section{Acknowledgements}

This study received funds from the SHISEIKAI Scholarship Fund for basic researchers of medical science, the Keiko Watanabe Award.

\section{Conflicts of Interest}

The authors declare no conflicts of interest regarding the publication of this paper.

\section{References}

[1] National Institute of Social Security and Population Problems (2017) Marriage and Childbirth in Japan Today: The Fifteenth Japanese National Fertility Survey, 2015 (Results of Singles and Married Couples Survey). Survey Series No. 35. (In Japanese)

[2] Nohara, M. and Kato, I. (2011) Child Raising Support for Working Parents: A Follow-Up Study at a Daycare Facility. Journal of Tokyo Women's Medical University, 81, 408-415. (In Japanese)

[3] Cabinet Office of Japanese Government (2017) Declining Birthrate White Paper 2017. (In Japanese)

[4] Michiko Nohara, M., Tomizawa, Y. and Saito, K. (2017) Frequency of Absence Due to Illness among Nursery Children. Journal of Tokyo Women's Medical University, 87, 146-150. (In Japanese)

[5] Ohkusa, Y., Sugawara, T., Mitani, M., Sugiura, H. and Okabe, N. (2011) Development and Evaluation of a School Absenteeism Reporting System. Japanese Journal School of Health, 53, 312-319. (in Japanese) 
[6] Sugawara, T., Fujimoto, T., Ohkusa, Y., Sugishita, Y., Konagaya, M., Sugiura, H., Taniguchi, K. and Okabe, N. (2012) The Possibility of Outbreak Control by Real-Time Surveillance with PCR Method Performed Immediately-A Case Study of Hand Foot and Mouth Disease Outbreak in a Day Care Facility for Children. Kansenshogaku Zasshi, 86, 405-410. (In Japanese) https://doi.org/10.11150/kansenshogakuzasshi.86.405

[7] Sugawara, T. and Ohkusa, Y. (2013) Two Aspects of Infectious Disease Surveillance at School and Nursery School: Early Response based on Early Detection and Recognition of Incidence of Infectious Diseases from Nursery School Kids to High School Students. The Journal of Child Health, 72, 610-612. (In Japanese)

[8] Watanabe, M., Kurita, J., Takagi, T., Nagata, N., Nagasu, N., Sugawara, T. and Ohkusa, Y. (2016) Early Detection and Response for Measles and Rubella Cases through the (Nursery) School Absenteeism Surveillance System in Ibaraki Prefecture. Nihon Koshu Eisei Zasshi, 63, 209-214. (In Japanese)

[9] Matsumoto, K., Sugawara, T. and Ohkusa, Y. (2015) The Influenza Outbreak in 2014/2015 Season, in Sumida Ward, through the (Nursery) School Absenteeism Surveillance System. Kansenshogaku Zasshi, 89, 748-749. (In Japanese) https://doi.org/10.11150/kansenshogakuzasshi.89.748

[10] Kurita, J., Sugawara, T., Matsumoto, K., Nakamura, Y. and Ohkusa, Y. (2018) Association among (Nursery) School Absenteeism Surveillance System and Incidence of Infectious Diseases. School Health, 14, 21-27.

[11] Schmidt, W.P., et al. (2010) School Absence Data for Influenza Surveillance: A Pilot Study in the United Kingdom. Eurosurveillance, 15, pii: 19467.

[12] Calvin, K., et al. (2012) Electronic School Absenteeism Monitoring and Influenza Surveillance, Hong Kong. Emerging Infectious Diseases, 18, 885-887. https://doi.org/10.3201/eid1805.111796

[13] Mogto, C.A.K., et al. (2012) School Absenteeism as an Adjunct Surveillance Indicator: Experience during the Second Wave of the 2009 H1N1 Pandemic in Quebec, Canada. PLoS ONE, 7, e34084. https://doi.org/10.1371/journal.pone.0034084

[14] Fan, Y., Yang, M., Jiang, H., Wang, Y., Yang, W., Zhang, Z., Yan, W., Diwan, V.K., $\mathrm{Xu}$, B., Dong, H., Palm, L., Liu, L. and Nie, S. (2014) Estimating the Effectiveness of Early Control Measures through School Absenteeism Surveillance in Observed Outbreaks at Rural Schools in Hubei, China. PLOS ONE, 9, e106856.

https://doi.org/10.1371/journal.pone.0106856

[15] Cheng, C.K.Y., Channarith, H. and Cowling, B.J. (2013) Potential Use of School Absenteeism Record for Disease Surveillance in Developing Countries, Case Study in Rural Cambodia. PLoS ONE, 8, e76859. https://doi.org/10.1371/journal.pone.0076859

[16] Besculides, M., et al. (2005) Evaluation of School Absenteeism Data for Early Outbreak Detection. BMC Public Health, New York.

[17] Matsumoto, K., Hirayama, C., Sakuma, Y., Itoi, Y., Sunadori, A., Kitamura, J., Nakahashi, T., Sugawara, T. and Ohkusa, Y. (2016) Case Study of Early Detection and Intervention of Infectious Disease Outbreaks in an Institution Using Nursery School Absenteeism Surveillance Systems (NSASSy) of the Public Health Center. Japanese Journal of Public Health, 63, 325-331. (In Japanese)

[18] http://www.mhlw.go.jp/bunya/koyoukintou/ikuji-kaigo01/

[19] Caicedo, C. (2015) Health and Functioning of Families of Children with Special Health Care Needs Cared for in Home Care, Long-Term Care, and Medical Day Care Settings. Journal of Developmental \& Behavioral Pediatrics, 36, 352-361. 
https://doi.org/10.1097/DBP.0000000000000167

[20] Caicedo, C. (2014) Families with Special Needs Children: Family Health, Functioning, and Care Burden. Journal of the American Psychiatric Nurses Association, 20, 398-407. https://doi.org/10.1177/1078390314561326 